\title{
The New 2017 Classification of
} Periodontal and Peri-Implant Diseases: A Malaysian PerioSymposium

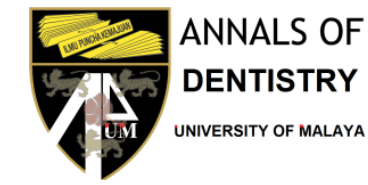

www.adum.edu.my

Ann Dent UM 2019, 26:59-61 Dol: 10.22452/adum.vol26no9

\author{
Debora C Matthews ${ }^{1}$, Betsy Thomas ${ }^{2}$, Bennete Fernandes ${ }^{3}$, \\ Ranjeet Bapat ${ }^{4}$, Tanay Vijaykumar Chaubal ${ }^{4}$ and Pulikkotil Shaju \\ Jacob $^{4 *}$
}

\section{KEYWORDS}

Periodontitis, Gingivitis, Consensus workshop, Disease progression

\begin{abstract}
The introduction of the recent 2017 classification of periodontal diseases has been welcomed by the periodontal fraternity. The new classification has used available evidence as the backbone for its development. It has been felt by many experts that a good understanding is required for its practice. Towards this, a Malaysian PerioSymposium was organised in May 2019 to comprehend the classification and also to identify the right path towards its learning among undergraduate students of dentistry in Malaysia. The symposium was conducted and moderated by local and international experts. Apart from the few limitations identified, the new classification was recommended to be taught in the undergraduate dental programme across schools in Malaysia.
\end{abstract}

\section{INTRODUCTION}

In 2017, a symposium to develop an evidencebased, consensus derived classification system for periodontal and peri-implant diseases and conditions was jointly supported by the American Academy of Periodontology and the European Federation of Periodontology. This World Workshop included expert participation from all over the world [1]. The development of a new system to classify periodontal diseases was

\footnotetext{
${ }^{1}$ Faculty of Dentistry, Dalhousie University, Canada ${ }^{2}$ Faculty of Dentistry, MAHSA University, Malaysia ${ }^{3}$ Faculty of Dentistry, SeGI University, Malaysia

${ }^{4}$ Division of Clinical Dentistry, International Medical University, Malaysia
}

*Correspondence: Shaju_Jacob@imu.edu.my necessitated by advances in knowledge from biological and clinical research that have emerged since the 1999 International Classification of Periodontal Diseases. It was supported by the strongest available research, including systematic reviews and meta-analyses where feasible [2]. The new classification defines clinical periodontal health in terms of intact and reduced periodontium, challenges the term aggressive periodontitis, and stages periodontitis based on disease severity while grading based on disease susceptibility. Most experts in the field of periodontology have welcomed the new classification but some have raised concerns on its implementation due to the complexities in the grading and staging of periodontitis [3]. Various periodontal societies are educating their clinicians, academics and researchers on the new classification. 
The Malaysian Society of Periodontology has organised a series of programmes to educate the general dentists and specialist on the new classification system. To augment the efforts of the Society and for further understanding, a Malaysian PerioSymposium was held on the $17^{\text {th }}$ May2018 in International Medical University and was conducted by the School of Dentistry. The authors of this paper formed the panel of international and local speakers who addressed the topic to an audience comprising of academics, general dentists, specialists in Periodontology and students of the dental programme. The authors represented their affiliated institutions which are planning to introduce the teaching of the new classification to the students of undergraduate dental programme. The symposium was designed to help attendees understand the new classification and to develop a roadmap for its implementation in the undergraduate curriculum of the dental school. The speakers introduced and explained the new classification through a series of presentations addressing the topic of (a) Periodontal Health, Gingival Diseases and Conditions, (b) Periodontitis and (c) Other conditions affecting the Periodontium. The attendees were then actively engaged in discussion and provided an opportunity to diagnose gingival and periodontal diseases through various clinical scenarios based on the new classification system. During discussion by the organisers and attendees, the following points were identified to help in the implementation plan of the new classification.

\section{HIGHLIGHTS OF THE CLASSIFICATION SYSTEM}

The 2017 World Workshop Classification system defines clinical health for the first time and distinguishes an intact and a reduced periodontium (i.e. reduced through disease or surgical intervention). The term 'aggressive periodontitis' is removed, as there is little evidence from biologic studies that chronic and aggressive periodontitis are separate entities as opposed to variations in the same disease process. The only other distinct diseases recognised are necrotising periodontitis and periodontitis as a manifestation of systemic disease.

It is now clearer that once a periodontitis patient, always a periodontitis patient. Even with gingival health and pockets of $4 \mathrm{~mm}$ or less, the diagnosis would be 'stable' periodontitis.
Disease severity is referred to as 'staging', based primarily upon interproximal attachment loss Stage 1 (early/mild) to Stage IV (very severe). The risk of progression of disease is now included in the diagnosis, which will assist in determining prognosis. A simple calculation of the percentage of bone loss over the patient's age determines a Grade of A (slow), B (moderate) or C (rapid), and can be followed by a statement of other risk factors such as smoking and uncontrolled diabetes.

\section{LIMITATIONS}

While the 2017 Periodontal and Periodontal Disease Classification system is quite clear and easy for general dentists and undergraduate students to understand, as with all new systems, there are some limitations. For example, the value of radiographs for diagnosis is not explicit. Due to lack of, or limited, evidence, the role of biomarkers has no role in determining diagnoses at this time. To date, no new system of prognostication categories has been developed based on the 2017 classification. The other major limitation is that the implications for treatment decisions based on this new classification system are not clear. With the elimination of the category of 'aggressive disease', do antibiotics still play a role in our periodontal treatment?

\section{OUTCOMES}

The new classification system is being rolled out world-wide and must therefore be part of all new undergraduate dental curricula, including that in Malaysian universities. Educators must have a thorough understanding of the strengths, limitations and application of 2017 Classification. However, until new guidelines are developed in alignment with the new classification, treatment decisions will still be based on the clinical judgement of clinician, the overall health of the patient and any risk factors that may be associated with the risk of disease progression.

\section{ACKNOWLEDGEMENT}

The authors would like to thank Professor Allan Pau Kah Heng, Dean, School of Dentistry, International Medical University for support towards the conduct of PerioSymposium. 


\section{DECLARATION OF INTEREST}

The authors report no conflicts of interest. The authors alone are responsible with the content of this article.

\section{REFERENCES}

1. Caton, J. G., Armitage, G., Berglundh, T., Chapple, I. L. C., Jepsen, S., Kornman, K. S., et al. A new classification scheme for periodontal and peri-implant diseases and conditions - Introduction and key changes from the 1999 classification. Journal of Periodontology 2018; 89:S1-S8.

2. Dietrich, T., Ower, P., Tank, M., West, N. X., Walter, C., Needleman, I., et al. Periodontal diagnosis in the context of the 2017 classification system of periodontal diseases and conditions - implementation in clinical practice. British Dental Journal 2019; 226(1):16-22.

3. Selvakumar, J., Jennifer, J., Parvin, S. S. Y., \& Shankar, N. G. Newer Classification of Periodontal And PeriImplant Diseases And Conditions-An Update. World Journal of Advanced Scientific Research, 2019;2(2):3952.

License Information: This work is licensed under a Creative Commons Attribution 